Politik Ekonomik Kuram 2019, Cilt 3(1), 105-112

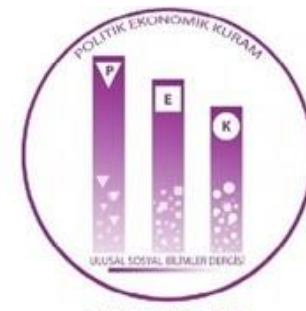

Cilt 3(1) 2019
Politik Ekonomik Kuram Dergi Web Sitesi: http://dergipark.gov.tr/pek

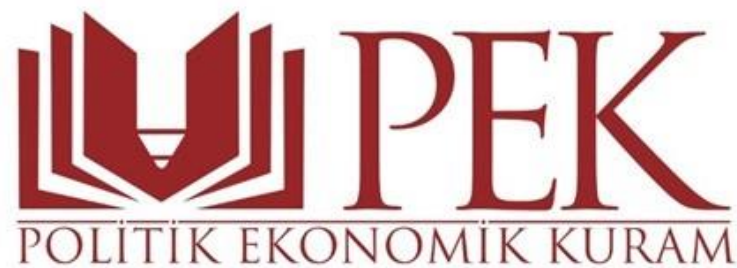

\title{
Doğrudan Yabancı Yatırımlar ve İş Yapma Kolaylığı: Türkiye Örneği ${ }^{1}$
}

\section{Zehra Doğan ÇALIŞKAN ${ }^{2}$}

\section{Makale Bilgileri}

Makale Geçmişi:

Makalenin Yüklendiği Tarih: 29.04.2019

Makalenin Kabul Edildiği Tarih: 11.06.2019

Anahtar Kelimeler: Doğrudan yabancı yatırımlar, iş yapma kolaylığı endeksi, Granger nedensellik analizi.

\footnotetext{
${ }^{1} \mathrm{Bu}$ çalışma 17-19 Nisan AICOSS Kongresinde sunulmuş bildirinin genişletilmiş halidir.

2 Dr. Öğretim Üyesi, Bolu Abant İzzet Baysal Üniversitesi, Gerede Uygulamalı Bilimler Fakültesi, Uluslararası Ticaret ve Lojistik Bölümü,
} 


\title{
Özet
}

Dünya Bankasının 2003 yılından beri yayınladığı iş yapma kolaylı̆̆ı endeksi raporları iş hayatını etkileyen düzenlemelerle ilgili sunduğu sayısal veriler yoluyla yatırım ortamının genel görünümü hakkında fikir sunmaktadır. Bu bağlamda raporlarda yer alan başlıklar ile yatırım ortamı arasında sıkı bir ilişkinin varlığından söz etmek mümkündür. Yatırım ortamının iyileşmesi, yabancı yatırımcıların yatııım yapma isteğini artırmakta; aynı zamanda üretim ve istihdamın artı̧ı ile milli gelirin büyümesinde önemli rol oynamaktadır. Bu nedenle iş yapma kolaylığı ile doğrudan yabancı yatırımlar arasında güçlü bir ilişki olduğu tahmin edilmektedir. Bu amaçla çalışmada Granger nedensellik analizi kullanılarak, Türkiye için 2003-2018 dönemi için, iş yapma kolaylığı endeksi ve doğrudan yabancı yatırımlar arasında ilişki kurulmuştur. Çalışma sonucunda iş yapma kolaylığından doğrudan yabancı yatırımlara doğru tek yönlü bir nedensellik ilişkisine rastlanılmıştır.

\section{Foreign Direct Investment and Doing Business: The Case of Turkey}

\begin{abstract}
The World Bank's business ease index reports, which have been published since 2003, provide insight into the regulations affecting business life. Ease of doing business index reports provides information about the overall view of the investment environment through numerical data. In this context, it is possible to mention between the content of the reports and the investment environment. Improving the investment environment increases the willingness of foreign investors to invest; it also plays an important role in the growth of national income with the increase in production and employment. Therefore, it is estimated that there is a strong relationship between ease of doing business and foreign direct investment. For this purpose, the relationship between ease of doing business and foreign direct investments has been established. The study was used in the Granger causality analysis for the period 2003-2018 in Turkey. As a result of the study, a one-way causality relationship from foreign companies to foreign direct investments has been observed.
\end{abstract}

Key Words: Foreign direct investment, ease of doing business, Grnager Casuality Test. 


\section{Giriş}

2003 yılından beri Dünya Bankası tarafından yayınlanan iş yapabilirlik endeksi (doing business) raporları ülkelerin yatırım ortamını etkileyebilecek şirket kuruluşu, vergi politikaları, istihdam, lisans alma süreci, yatırımcıların korunması gibi çeşitli göstergeleri temel alarak karşılaştırmalı bir değerlendirme sunmakta ve yatırım ortamının genel görünümünü sunmaktadır. Raporda, bir işletmeyi kurma ve devam ettirme konularında devletin koyduğu şartları yerine getirme, ülkeler arası ticaret, vergi ödeme ve bir işletmeyi kapatma gibi işlemlerin süre ve maliyetleri ortaya konulmaktadır. İş yapabilirlik endeksi şu başlıklardan oluşmaktadır:

- $\quad$ İşe başlama işlemleri,

- İnşaat izinlerinin alınması işlemleri,

- $\quad$ Elektrik bağlatma işlemleri,

- $\quad$ Tapu siciline kayıt işlemleri,

- Kredi alma işlemleri,

- $\quad$ Azınlık pay sahibi yatırımcılarının korunması işlemleri,

- $\quad$ Vergilerin ödenmesi işlemleri,

- Sınır ötesi ticaret işlemleri,

- Sözleşmelerin uygulanması işlemleri,

- $\quad$ İflasın çözümü işlemleri

- İstihdam mevzuatının esnekliği ve iş kalitesinin özellikleri

Yatırım ortamının uygunluğunu ölçen endeksler sadece yerel girişimciler için değil yabancı girişimciler için de önemli bir göstergedir. Bu göstergeler aracılığı ile yatırım kararı alan yerli ve yabancı yatırımcılar istihdamı ve büyümeyi etkilemektedir. Bu bakımdan iş yapma kolaylığ endeksinin bir diğer deyişle yatırım ortamının uygunluğunun doğrudan yabancı yatırımlar üzerindeki etkisinin ne olduğunu belirlemek yatırım ortamının olumsuz koşullarının azaltılması bakımından önem arz etmektedir. 
Doğrudan yabancı sermaye yatırımları gelişmiş ve gelişmekte olan ülkeler açısından oldukça önemlidir. Gelişmiş ülkelerde sürdürebilir büyümenin sağlanması, gelişmekte olan ülkelerde ise istihdam ve katma değer ile ekonomik büyüme ve kalkınmanın başlatılması ile devamlılı̆̆ açısından önemlidir. $\mathrm{Bu}$ nedenle ülkeler doğrudan yabancı sermaye yatırımlarını kendi ülkelerine çekebilmek için politikalar üretmek, var olan sorunları çözümleyici tedbirler almak gibi yöntemler izlerler. Bu bağlamda çalışmada Türkiye için 2003-2018 yılları arasında doğrudan yabancı yatırımlar ve iş yapma kolaylığı endeksi arasında ilişki açıklanmaya çalışılmıştır. Beklenti iş yapma kolaylığı endeksi değerleri iyileştikçe diğer bir ifade ile yatırım ortamı iyileştikçe doğrudan yabancı yatırımların artması yönündedir.

\section{Teorik Çerçeve ve Literatür Özeti}

Literatürde yapılan çalışmalarda iş yapma kolaylığının doğrudan yabancı yatırımları pozitif yönde etkilediği bulgulanmıştır. Ancak literatüre göre bu etki gelişmekte olan ülkelerde daha fazla hissedilmektedir. Literatüre göre alt gelir grubundaki ülkelerde yatırım altyapısının yetersizliği, üst gelir grubundaki ülkelerde yolsuzluk ve zaten ticarete yoğun entegre olunması gibi nedenlerle doğrudan yabancı yatırımların etkisi fazla hissedilememektedir. Literatürün bu bakış açısından hareketle Türkiye yatırım ortamını iyileştirdiği ölçüde doğrudan yabancı yatırımların büyüme ve istihdam üzerindeki etkisi daha fazla hissedilebilinecektir.

Jayasuriya (2011) dinamik panel analizini kullandıkları çalışmalarında orta gelir seviyesindeki ülkeler için 2006-2009 yılları arasında doğrudan yabancı yatırımlar ve iş yapma kolaylığı endeksi arasında ilişki kurmuştur. Analiz sonucunda iş yapma kolaylığı iyileştikçe doğrudan yabancı yatırımların arttı̆̆ bulgulanmıştır.

Bayraktar (2013) çalışmasında doğrudan yabancı yatırımlar ile yatırım ortamını etkileyen iş yapma kolaylığı ilişkisini araştırmıştır. Çalışmada 2004-2010 yılları arasında gelişmiş ülkelerden gelişmekte olan ülkelere doğru yatırımların kayma nedenleri, iş yapma kolaylığı ile yabancı yatırımların çekiciliğgi konuları araştırılmıştır. Sonuç olarak iş yapma kolaylığı ile gelişmekte olan ülkelerde yatırım ortamı çekiciliği (yatırım kolaylığı) arasında pozitif yönlü ilişki bulunmuştur. 
Corcoran ve Gillanders (2013) çalışmasında 2004-2009 dönemi için iş yapma kolaylığı endeksi ile yabancı yatırımlar arasındaki ilişkiyi inceledikleri çalışmalarında OECD verilerine göre orta gelir grubundaki ülkelerde iş yapma kolaylığı arttıkça yabancı yatırımlar artmakta iken bu durum düşük ve alt gelir grubundaki ülkeler için geçerli olmamaktadır.

Bobenic-Hintosova ve Kubikova ve Rucinsky (2016) çalışmasında 2005-2015 dönemi için merkez Avrupa ülkelerinde iş ortamının doğrudan yabancı yatırımlar üzerinde etkili olup olmadığını incelemişlerdir. Analiz sonucunda yatırım ortamının kolaylığının yatırım girişleri için önemli olduğu ancak fazla küreselleşmiş merkez Avrupa ülkeleri için bu durumun geçerli olmadığı sonucuna varılmıştır.

MogesEbero ve Begum (2016) çalışmasında doğrudan yabancı yatırımlar ile iş yapma kolaylığ arasındaki ilişkiyi Etiyopya için araştırmışlardır. Buna göre 2004-2014 yıllarında Etiyopya'da dorudan yabancı yatırımlar ile iş yapma kolaylığı bileşenleri arasında pozitif ilişki bulgulanmıştır.

Mastar-Özcan ve Kayalıdere (2017) çalışmasında Türkiye için Onuncu Kalkınma planının yatırım ortamının iyileştirilmesi amacına uygun olarak iş yapma endeksine göre yatırım ortamının geliştirilmesine yönelik çalışmalar değerlendirilmiştir.

Nangpiire ve Rodrigues ve Adam (2018) çalışmasında Sahra altı Afrika ülkelerinde doğrudan yabancı yatırımlar ile iş yapma kolaylığı ilişkisini incelemişlerdir. Genişletilmiş en küçük kareler yönteminin uygulandığı çalışmada 44 Sahra altı Afrika ülkesi için iş yapma kolaylığı arttıkça 0,56 oranında yatırımların arttığı bulgulanmıştır.

Hassain vd. (2018) çalışmasında iş yapma kolaylığının işe başlama işlemleri, inşaat izinlerinin alınması işlemleri, elektrik bağlatma işlemleri, tapu siciline kayıt işlemleri, kredi alma işlemleri alt göstergeleri ile doğrudan yabancı sermaye yatırımları arasında 177 ülke için en küçük kareler yöntemi ile analiz yapmışlardır. Analiz sonucunda doğrudan yabancı sermaye yatırımları ile tapu siciline kayıt işlemleri, kredi alma işlemleri ile negatif, işe başlama işlemleri, inşaat izinlerinin alınması işlemleri ile arasında pozitif ilişki bulgulanmıştır. 


\section{Veri seti ve Yöntem}

Çalışmada Türkiye için 2003-2018 yılları arasında doğrudan yabancı yatırımlar ve iş yapma kolaylığı endeksi arasında ilişki açıklanmaya çalışılmıştır. Bu amaçla birim kök, Johansen eşbütünleşme ve Granger nedensellik analizleri uygulanmıştır. Çalışmada doğrudan yabancı yatırımlar Türkiye için cari dolar kuru üzerinden net girişler şeklinde Dünya Bankası veri tabanından elde edilmiştir. İş yapma kolaylığı verileri de yine dünya bankasının her yıl yayınladığı iş yapma kolaylığı (Doing Business) raporlarından elde edilmiştir.

\section{Analiz Sonuçları}

Çalışmada Türkiye'nin 2003-2018 yılları arasında Doğrudan Yabancı Yatırımları Miktarı ile İş Yapma Kolaylığı endeksi değerlerinin durağan olup olmadıkları Kwiatkowski-PhillipsSchmidt-Shin (KPSS) testine göre araştırılmış, iki değişkeninde düzey değerlerinde durağan olmadıkları ancak sabit ve trendli model kullanılıp ilk farkları alındığında yüzde 5 önem seviyesinde durağan hale geldikleri tespit edilmiştir. Tablo 1'de durağanlık testi sonuçları görülmektedir.

Tablo 1. KPSS Durağanlık Testi Sonuçları

\begin{tabular}{|c|c|c|c|}
\hline Değişkenler & & $\begin{array}{l}\text { Düzey değerleri } \\
\text { (Sabit ve Trendli) }\end{array}$ & $\begin{array}{l}\text { Birinci Fark Değerleri } \\
\text { (Sabit ve Trendli) }\end{array}$ \\
\hline \multirow{4}{*}{ DYY } & KPSS Statistic & 0.127050 & $0.160644 * *$ \\
\hline & $\% 1$ & \multicolumn{2}{|c|}{0.216000} \\
\hline & $\% 5$ & \multicolumn{2}{|c|}{0.146000} \\
\hline & $\% 10$ & \multicolumn{2}{|c|}{0.119000} \\
\hline \multirow{4}{*}{ İş yapma Kolaylığı } & KPSS Statistic & 0.122884 & $0.178340 * *$ \\
\hline & $\% 1$ & \multicolumn{2}{|c|}{0.216000} \\
\hline & $\% 5$ & \multicolumn{2}{|c|}{0.146000} \\
\hline & $\% 10$ & \multicolumn{2}{|c|}{0.119000} \\
\hline
\end{tabular}

Değişkenlerin benzer şoklardan etkilenip etkilenmedikleri hususu Johansen Eş Bütünleşme testi yardımıyla araştırılmıştır. Tablo 2'de Johansen eşbütünleşme analizi sonuçlarına göre elde edilen bulgular 0,05 önem seviyesinde bir adet eş bütünleşik eşitlik bulunduğunu göstermektedir. Başka bir ifade ile seriler arasında uzun dönemli bir ilişki mevcuttur. 
Tablo 2. Johansen Eşbütünleşme Testi Sonuçları

\begin{tabular}{|c|c|c|c|c|c|c|c|c|c|}
\hline \multicolumn{2}{|c|}{ Hipotezler } & \multicolumn{4}{|c|}{ İz İstatistiği Değerleri } & \multicolumn{4}{|c|}{ Maksimum Öz Değer İstatistikleri } \\
\hline $\mathbf{H}_{0}$ & $\mathbf{H}_{1}$ & Öz değer & $\begin{array}{l}\text { Test } \\
\text { istatistiği }\end{array}$ & \begin{tabular}{|l|} 
K,05 \\
Kritik \\
değer
\end{tabular} & $\begin{array}{l}\text { Olasilık } \\
\text { (p) }\end{array}$ & Öz değer & \begin{tabular}{|l|} 
Test \\
istatistiği
\end{tabular} & \begin{tabular}{|l|}
$\mathbf{0 , 0 5}$ \\
Kritik \\
değer
\end{tabular} & $\begin{array}{l}\text { Olasilık } \\
\text { (p) }\end{array}$ \\
\hline $\mathrm{r}=0$ & $\mathrm{r} \geq 1$ & 0.773136 & 22.85596 & 15.49471 & 0.0033 & 0.773136 & 20.76765 & 14.26460 & 0.0041 \\
\hline$r \leq 1$ & $r \geq 2$ & 0.138573 & 2.088311 & 3.841466 & 0.1484 & 0.138573 & 2.088311 & 3.841466 & 0.1484 \\
\hline
\end{tabular}

Tablo 3'de değişkenler arasındaki ilişkinin yönünü belirlemek için yapılan Granger Nedensellik testi sonuçları görülmektedir. Buna göre, iş yapma kolaylığı endeksinden doğrudan yabancı yatırımlara doğru tek yönlü bir nedensellik mevcuttur.

Tablo 3. Granger Nedensellik Sonuçları (1 Gecikmeli Model)

\begin{tabular}{|l|c|c|c|}
\hline Ho Hipotezi & n & F-İstatistiği & Olasılık \\
\hline KOLAYLIK, DYY'ın Granger nedeni değildir. & \multirow{2}{*}{15} & 4.88774 & 0.0472 \\
\cline { 1 - 1 } & & 0.37862 & 0.5498 \\
\hline
\end{tabular}

\section{Sonuç}

Doğrudan yabancı yatırımlar, kaynağı ve altyapısı yetersiz olan ülkelerde büyümenin tetikleyicisi olabilir. Bu bağlamda iş yapma ortamının şeffaf, kolay ve çözüme yönelik tedbirler alıyor olması doğrudan yabancı yatırımların ülkeye çekilebilmesi için önem arz etmektedir. Bu bakış açısında hareketle çalışmada Türkiye için doğrudan yabancı yatırımlar ile iş yapma kolaylığı arasındaki ilişki test edilmiştir. Analiz sonucunda iş yapma kolaylığından yabancı yatırımlara doğru bir nedensellik keşfedilmiştir. Bu bulgu teorik beklentiye uygun ve mevcut literatür ile uyuşan niteliktedir. Öte yandan henüz Türkiye için bu alanda literatürde ampirik çalışma mevcut olmadığından çalışma bu alana katkıda bulunmaktadır. Bununla birlikte iş yapma kolaylığı endeksinin henüz 2003 yılında yayımlanmaya başlamış olması gelecekte farklı testler ile farklı politika önerilerinin ortaya konulabilineceğini göstermektedir. Mevcut veri ile yapılan çalışmada, doğrudan yabancı yatırımlar ve iş yapma kolaylığı arasında eşbütünleşik ve tek yönlü bir nedensellik bulgulanmıştır. 


\section{Kaynakça}

Bayraktar, N. (2013). Foreign Direct Investment and Investment Climate, International Conference on Applied Economics (ICOAE) 2013, Procedia Economics and Finance, $83-92$.

Bobenic-Hintosova, A. ve Kubikova, Z. ve Rucinsky, R. (2016). Does Quality Of Busıness Environment Influence Fore1gn Direct Investment Inflows? A Case Of Central European Countries, Central European Journal Of Management 3(1), 5-13, Avaliable from: https://journals.muni.cz/cejm/index.

Corcoran, A. ve Gillanders, R.(2013). Foreign Direct Investment and The Ease of Doing Business, No 201219, pp. 1-24, Working Papers from School of Economics, University College Dublin, Avaliable from: https://econpapers.repec.org/paper/ucnwpaper/201219.htm

Hossain, M.T. ve Hassan, Z. ve Shafiq, S. ve Basit A. (2018) Ease of Doing Business and Its Impact on Inward FDI, Indonesian Journal of Management and Business Economics, 1(1), 52-65, https://papers.ssrn.com/sol3/papers.cfm?abstract_id=3219641.

Jayasuriya, D. (2011). Improvements in the World Bank's Ease of Doing Business Rankings: Do They Translate into Greater Foreign Direct Investment Inflows? World Bank Policy Research Working Paper No. 5787. Available at SSRN: https://ssrn.com/abstract=1923545.

Mastar Özcan, P. ve Kayalıdere, G. (2017) Türkiye'de İş Ve Yatırım Ortamının Dünya İş Yapma Endeksine Göre Değerlendirilmesi, Journal of Social And Humanities Sciences Research (JSHSR) 2017 Vol:4 Issue:5 pp:819-825.

MogesEbero, E. ve Begum, M. (2016). The Desirability Of Doing Business And Flow Of Foreign Direct Investment Nexus: The Case of Ethiopia, International Research Journal of Engineering and Technology (IRJET), Volume: 03 Issue: 05, https://www.irjet.net/archives/V3/i5/IRJET-V3I5421.pdf

Nangpiire, C. ve Rodrigues, R.G. ve Adam, I.O. (2018). Ease Of Doing Business And Foreign Direct Investment Inflow Among Sub-Sahara African Countries, International Journal of Business and Emerging Markets, Vol. 10, No. 3, 2018, ss.289-315. 